WellBeing International

WBI Studies Repository

$6-2013$

\title{
Are Juvenile Domestic Pigs (Sus scrofa domestica) Sensitive to the Attentive States of Humans? The Impact of Impulsivity on Choice Behaviour
}

\author{
Christian Nawroth \\ Martin Luther Universitat Halle-Wittenberg \\ Mirjam Ebersbach \\ University of Kassel \\ Eberhard von Borell \\ Martin Luther Universitat Halle-Wittenberg
}

Follow this and additional works at: https://www.wellbeingintlstudiesrepository.org/attent

Part of the Animal Studies Commons, Comparative Psychology Commons, and the Other Animal Sciences Commons

\section{Recommended Citation}

Nawroth, C., Ebersbach, M., \& von Borell, E. (2013). Are juvenile domestic pigs (Sus scrofa domestica) sensitive to the attentive states of humans?-The impact of impulsivity on choice behaviour. Behavioural processes, 96, 53-58.

This material is brought to you for free and open access by WellBeing International. It has been accepted for inclusion by an authorized administrator of the WBI Studies Repository. For more information, please contact wbisr-info@wellbeingintl.org.

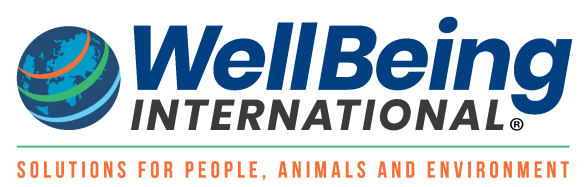


Are juvenile domestic pigs (Sus scrofa domestica) sensitive to the attentive states of humans? - The impact of impulsivity on choice behaviour.

Christian Nawroth*1 ${ }^{1}$, Mirjam Ebersbach ${ }^{2}$, Eberhard von Borell ${ }^{1}$

${ }^{1}$ Department of Animal Husbandry \& Ecology, Institute of Agricultural and Nutritional Sciences, Martin-Luther-University, Halle, GER

${ }^{2}$ Department of Developmental Psychology, Institute of Psychology, University of Kassel, Kassel, GER

\section{Corresponding author}

Christian Nawroth

Department of Animal Husbandry \& Ecology

Institute of Agricultural and Nutritional Sciences

Theodor-Lieser-Str. 11

06120 Halle, Germany

Phone: +49-345-5522336

Fax: +49-345-5527106

Email address: nawroth.christian@gmail.com 


\begin{abstract}
Previous studies have shown that apes, dogs and horses seem to be able to attribute attentive states to humans. Subjects chose successfully between two persons: one who was able to see the animal and one who was not. Using a similar paradigm, we tested a species that does not rely strongly on visual cues, the domestic pig (Sus scrofa domestica). Subjects could choose between two unfamiliar persons, with only one showing attention, in three different conditions (body, head away, body turned - head front). Subjects $(n=16)$ only showed a tendency towards the attentive human in the head away condition. However, by pooling those two conditions where the position of the human head was the only salient cue, we found a significant preference for the attentive person. Moreover, two approach styles could be distinguished - an impulsive style with short response times and a non-impulsive style where response times were relatively long. With the second approach style, pigs chose the attentive person significantly more often than expected by chance level, which was not the case when subjects chose impulsively. These first results suggest that pigs are able to use head cues to discriminate between different attentive states of humans.
\end{abstract}

Keywords: attentive state; domestic pig; human-animal interaction; social cognition 


\section{Introduction}

Being able to attribute attentive states to con- or heterospecifics has advantages in situations of predation and food monopolization (Kummer, 1967). It allows, for instance, to know if one is observed by another individual or not. In an initial study, Povinelli and Eddy (1996) showed that young chimpanzees, at least after some training (but see Bulloch et al., 2008), could distinguish between humans that were able to see them or not when begging for food. Only the attentive human would provide food immediately, or would provide food at all. Different test situations were presented to the chimpanzees in which the body and head orientation of the two humans to beg from were altered or different items to cover the sight of one of them were applied. The same paradigm has been used in studying attention recognition in several other primate (gorillas: Bania and Stromberg, 2012; lemurs: Botting et al., 2011) and non-primate species (horses: Proops and McComb, 2010; dogs: Gacsi et al., 2004). The begging paradigm was also modified (Hattori et al., 2007; Hostetter et al., 2001; Kaminski et al., 2004; Tempelmann et al., 2011) and applied in competitive situations (Flombaum and Santos, 2006; Sandel et al., 2011), involving either one or two persons.

Several species tested with this original paradigm, especially dogs and horses, are likely to have year-long daily interaction with humans including a long training history. For instance, a dog would preferably approach a human who is looking towards him because he is used to get a reward from humans being oriented to them. This fact raised a considerable controversy about the impact of ontogeny and domestication on dog's behavior in sociocognitive (Hare et al., 2002; Hare and Tomasello, 2005; Udell et al., 2008) and, in particular, perspective taking tasks (Roberts and McPherson, 2011; Udell et al., 2011; Viranyi and Range, 2011).

The domestication of the pig started more than 9000 years ago (Umberto, 2007) from several spots in Eurasia, making it to one of the oldest domesticated species. However, pigs 
where not selected for companionship, sport or hunting purposes during their domestication history, as it was the case for dogs and horses. Consequently, compared to the latter two species, behavioral studies with pigs covering their cognitive traits in general and humananimal-communication in particular are underrepresented. In contrast, pigs are subjects of interest in applied ethology and medical research because of their use in meat production and their physiological similarities to humans (Kornum and Knudsen, 2011). Nonetheless, behavioural research in pigs showed that they are able to remember different food locations (Mendl et al., 1997) as well as the value of different food sites (Held et al., 2005). Additionally, a recent study by Kouwenberg and colleagues (2009) suggests that pigs do not only remember the "where” and "what” but also the "when” of events. This might serve as evidence of episodic-like memory in domesticated animals, which leads to potential implications related to animal welfare (Mendl and Paul, 2008). While relying less on visual cues, pigs also showed sophisticated skills when using a mirror to obtain information about the location of a reward (Broom et al., 2009).

In a recent study, Albiach-Serrano and colleagues (2012) introduced an object choice task to compare domestic pigs from differently enriched environments with wild boars concerning their capabilities to interpret physical and social cues. Contrary to what one would expect from the domestication hypothesis (Hare et al., 2002), they found that only wild boars solved tasks involving specific social cues (i.e., pointing), whereas domestic pigs from less enriched environments were more prone to solve physical tasks (i.e., an inclined board that covered a piece of food). The authors claimed that specific experiences in pigs' development rather than domestication effects account for those results. However, the sample size of wild boars was quite small. In addition, they tested subjects behind a mesh that separated them from the experimenter. Even as this setup is under some circumstances necessary (e.g. for 
safety reasons), this setup has been criticized in other studies with dogs (e.g. Udell et al., 2008) as a barrier seems to distract subjects and therefore performance may decrease.

However, controlled experiments where pigs had to adjust their behavior to that of hetero- or conspecifics are rare. Notable exceptions are studies of Held et al. (2000; 2001; 2002). In one study, Held et al. (2001) allowed pigs to follow two companion pigs - one was able to see the baiting of food and the other was not. Most pigs did not follow their companions, probably to avoid competitive and aggressive behavior. Nonetheless, out of ten pigs, two subjects followed their conspecifics and one of them followed the "knowing" individual significantly more often than the "not knowing” individual, suggesting that pigs, to some degree, might be able to take the visual perspective of others.

Here we present the first study examining the ability of domestic pigs to discriminate between attentive and inattentive heterospecific individuals (i.e., humans). The experiment started with a short training phase. Here, pigs were rewarded for approaching two experimenters, closely kneeing at the same spot and facing each other. After habituation to the experimenters, individuals received test trials with three different conditions, where subjects could, without being rewarded, approach either the attentive or the inattentive person. As in other studies (Gasci et al., 2004; Proops and McComb, 2010), we additionally measured subjects' response times. Furthermore, we checked if pigs moved straight to an experimenter or if they, for instance, changed direction, startled or stopped moving and looked at both experimenters. This served as an indicator of whether the subjects' gained additional information of their environment or not (hence, if they used an "impulsive" or "nonimpulsive” approach style). We predicted that pigs would approach the attentive person when given a choice, although the performance level might be lower compared to other species that were tested in this paradigm due to less human contact of pigs and no pre-existing training histories. 


\section{Methods}

\subsection{Subjects}

A total of 34 pigs participated. Subjects were tested in two groups: Group 1 (20 pigs at the age of 13 weeks at the beginning of testing) and Group 2 (14 pigs at the age of 16 weeks at the beginning of testing). Two subjects of Group 1 and three subjects of Group 2 were excluded from testing as they were injured or showed signs of arousal during the end of the habituation phase. Pigs had water and food access ad libitum all the time. Subjects of Group 1 had participated before testing in a nutritional experiment where they were single housed. Subjects of Group 2 had participated in a light intensity experiment. None of these experiments involved any choice tasks or close human-animal contacts. Nonetheless, three subjects of Group 2 additionally participated in an object choice task prior to testing, including pointing and gaze cues (xx, unpublished data). They were fed with pieces of apples placed under a bucket but did not receive food directly from the handler.

\subsection{Housing}

Pigs were group-housed in a barn of the Institute of Agricultural and Nutritional Sciences in Merbitz, Germany, in two pig pens (250 x $400 \mathrm{~cm}$ ) with straw bedding, each containing seven or ten pigs, depending on group size. Temperature was maintained at about $23^{\circ} \mathrm{C}$ and artificial light was provided from 7 am to 5 pm.

\subsection{Pre-experimental habituation phase}

After transferring subjects to the pig pens, they got five days of habituation to decrease aggressiveness and make them familiar with the new environment. Subsequently, pigs 
received five days of habituation to the test and the resting area before the experiments started. During the first two days, they were introduced pair wise for about 15 min to both areas. On the third and fourth day, they were introduced alone, again for about 15 minutes. On the fifth day of habituation, they were trained to snout a yellow bucket, positioned in the test area, to receive a slice of apple that was located under the bucket. After training for the bucket, the pig was forced to go to the resting area and the entrance was closed by a transparent sliding door. The yellow bucket was positioned in the test area about one meter away from the door. As soon as the subject was waiting behind the sliding door, it was opened and the pig could get the reward by touching the bucket with its snout. This was repeated five times at minimum and for some individuals as long as they needed to approach the bucket immediately. This procedure was introduced to increase subjects' visual search behavior in the experiment.

\subsection{Test Procedure}

Before the testing began, two unfamiliar experimenters entered the pigs' home pens for some minutes to make them familiar with the new olfactory and visual cues. Thereafter, pigs were individually transferred into the test area, where the two unfamiliar experimenters were standing so the pigs could explore and get familiar with the new cues in the testing environment. After some minutes of habituation, the training trials began. Pigs were slightly forced by the experimenters to go to the resting area and the sliding door was left open. The two experimenters took position, kneeing in the middle of the test area about $200 \mathrm{~cm}$ away from the entrance (training point ' $T$ ', see Fig. 1). During training, experimenters were facing each other, not looking at the subject. Each hold one piece of apple in one hand and their position (left/right) was balanced during training trials. The pig was free to enter the test area 
and to get the reward from the hand. It is important to mention that none of the pigs, to our best knowledge, was fed by hand before or was directly rewarded for approaching a human. After three to five trials, each pig went straight to the experimenter after entering the test area and proceeded therefore to the test phase. The subject, again, was forced slightly to leave the test arena and the entrance was closed by the sliding door. The experimenters went onto position with a distance of $240 \mathrm{~cm}$ between them and the distance between door and experimenter was about $230 \mathrm{~cm}$ (see Fig. 1). 


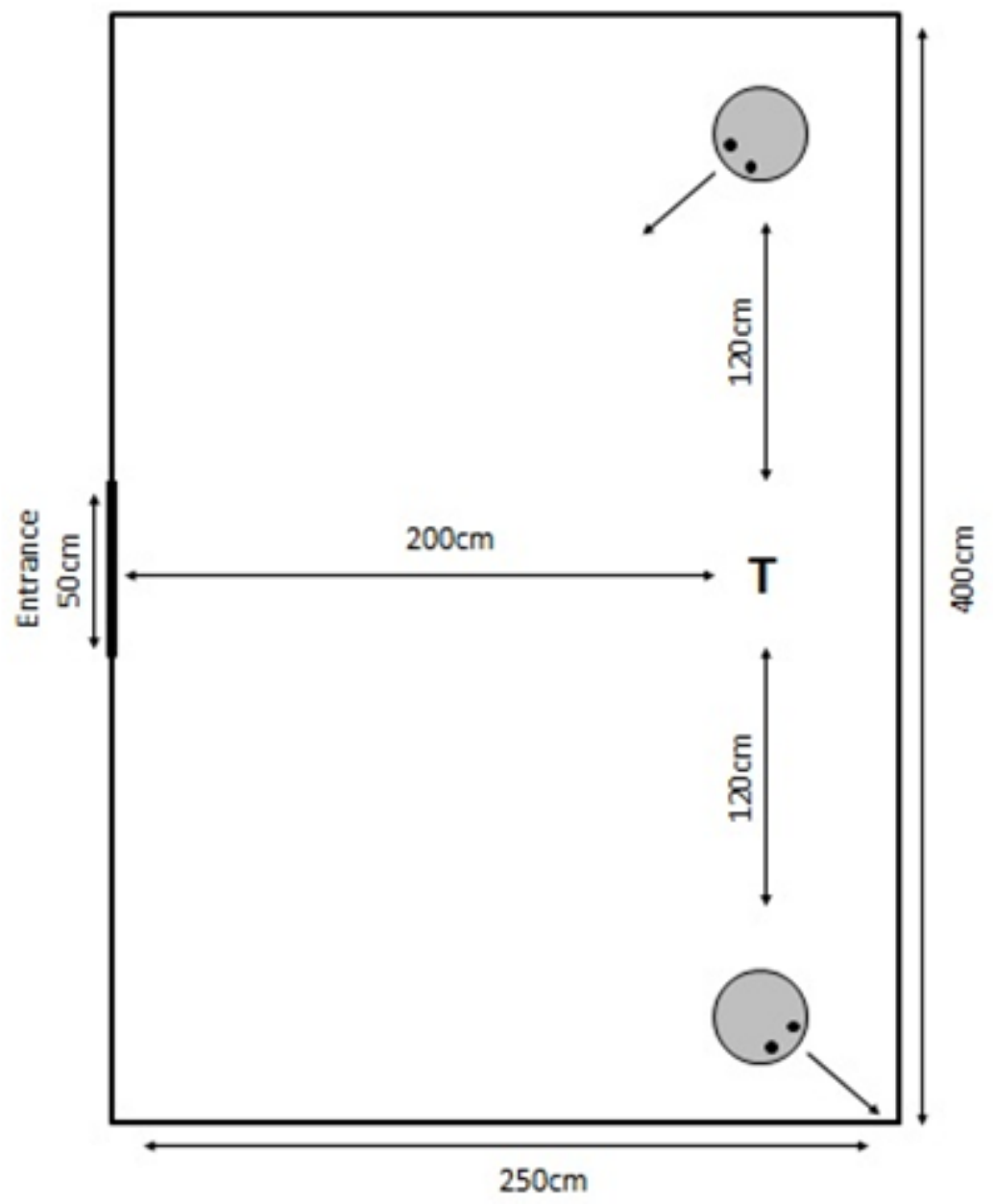

Fig. 1 Measurements of the test area including the two experimenters, located on either the left or right opposite corner of the entry as well as the distances between entrance and training point $(\mathrm{T})$ and between the experimenters in the test. The door to the resting area is on the left side. Measurements of the resting area on the left are the same as in the test area.

We introduced three test conditions (Fig. 2):

(1) body: One experimenter oriented her body and head to the entrance that was passed by the pig, the other experimenter oriented her body and head into the opposite direction, away from the entrance. 
(2) head away: Both experimenters oriented their bodies to the entrance while one was looking at the entrance and the other one was looking in the opposite direction.

(3) body turned - head front: Both experimenters oriented their bodies away from the entrance while one was turning her head and was looking at the entrance.

Body

Head away

Body turned - Head front
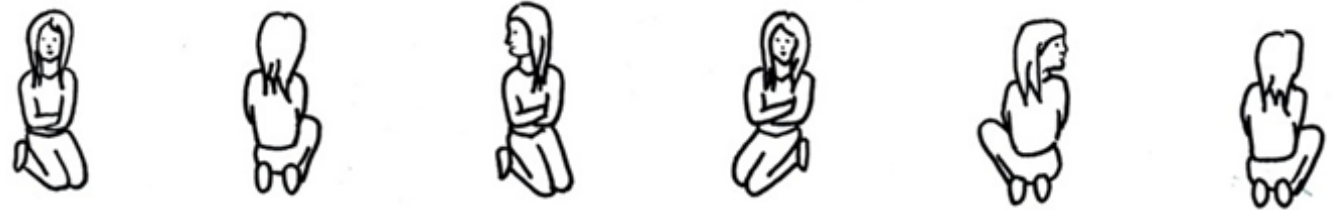

Fig. 2 Schematic images of the three test conditions. Only one of the two experimenters was looking at the entrance and was therefore attentive to the entering pig.

Both experimenters were always in a kneeing position to help pigs discriminating head and body position. Both crossed their arms in front of their chest so that their hands were not visible to the subjects. Each subject received in total two sessions of testing on two consecutive days. Each session included six trials, two for each condition. In total, each subject received four trials in each condition. Conditions were counterbalanced for side (left/right) and experimenter (E1/E2). The attentive person was never more than two consecutive trials on the same side. Pigs were never rewarded in test trials. To ensure motivation, a training trial followed after each test trial.

\subsection{Data scoring and analysis}


All trials were videotaped. An approach was scored as successful when subjects touched one experimenter with their snout. The number of correct choices was not distributed normally, therefore we used non-parametric tests (Wilcoxon-signed-rank-test) to examine whether pigs as a group performed above chance level. To test for potential effects of age and sex, we used Mann-Whitney-U-Tests. Additionally, we measured the response times using Interact ${ }^{\mathrm{tm}}$. Response times were defined as the time between a subjects' first step into the test arena and the moment at which it touched an experimenter. The potential effects of trial type and response accuracy (correct/incorrect) on the response times were analyzed as fixed factors in a Linear Mixed Model. We also scored subject's approach styles. An approach was coded as impulsive when a pig went straight to one experimenter whereas a non-impulsive approach included a change in the direction, or the startling and looking at both experimenters before making a choice. To test whether the number of correct choices with one approach style was above chance level we used a trial-by-trial analysis using a Chi-square Test. A second observer coded $25 \%$ of the test trials. Inter-observer reliability for choice (Cohen's $k=0.96$ ), response time (Pearson's $r=0.94$ ) and approach style (Cohen's $k=0.77$ ) was excellent. 


\section{Results}

From 29 pigs, 13 had to be excluded for several reasons: side bias $(n=4)$; stopping to make choices during the test session $(n=4)$; not finishing training $(n=4)$; aversion against the sliding mesh $(n=1)$. Thus, the data of 16 subjects were analyzed (Group 1: 2 males; 7 females; Group 2: 4 males; 3 females). The remaining pigs learned quickly to approach the experimenters directly in the training trials (Session $1: M=4.16, S E M=.14$ trials; Session 2: all pigs only needed three trials).

Table 1 Number of subjects with different performance levels (i.e. $0 \%, 25 \%$, 50\%, $75 \%$ or $100 \%$ correct choices out of four trials in each of the three conditions)

\begin{tabular}{|c|c|c|c|c|c|c|c|}
\hline \multirow[t]{2}{*}{ Condition } & \multicolumn{5}{|c|}{ Performance } & Mean (\#) & Mean (\%) \\
\hline & $0 \%$ & $25 \%$ & $50 \%$ & $75 \%$ & $100 \%$ & \pm SEM & \pm SEM \\
\hline Body & 2 & 4 & 5 & 4 & 1 & $1.88 \pm .29$ & $46.9 \pm 7.1$ \\
\hline Head away & - & 1 & 9 & 6 & - & $2.31 \pm .15$ & $57.8 \pm 3.8$ \\
\hline Head front & - & 3 & 5 & 8 & - & $2.31 \pm .20$ & $57.8 \pm 5.0$ \\
\hline
\end{tabular}




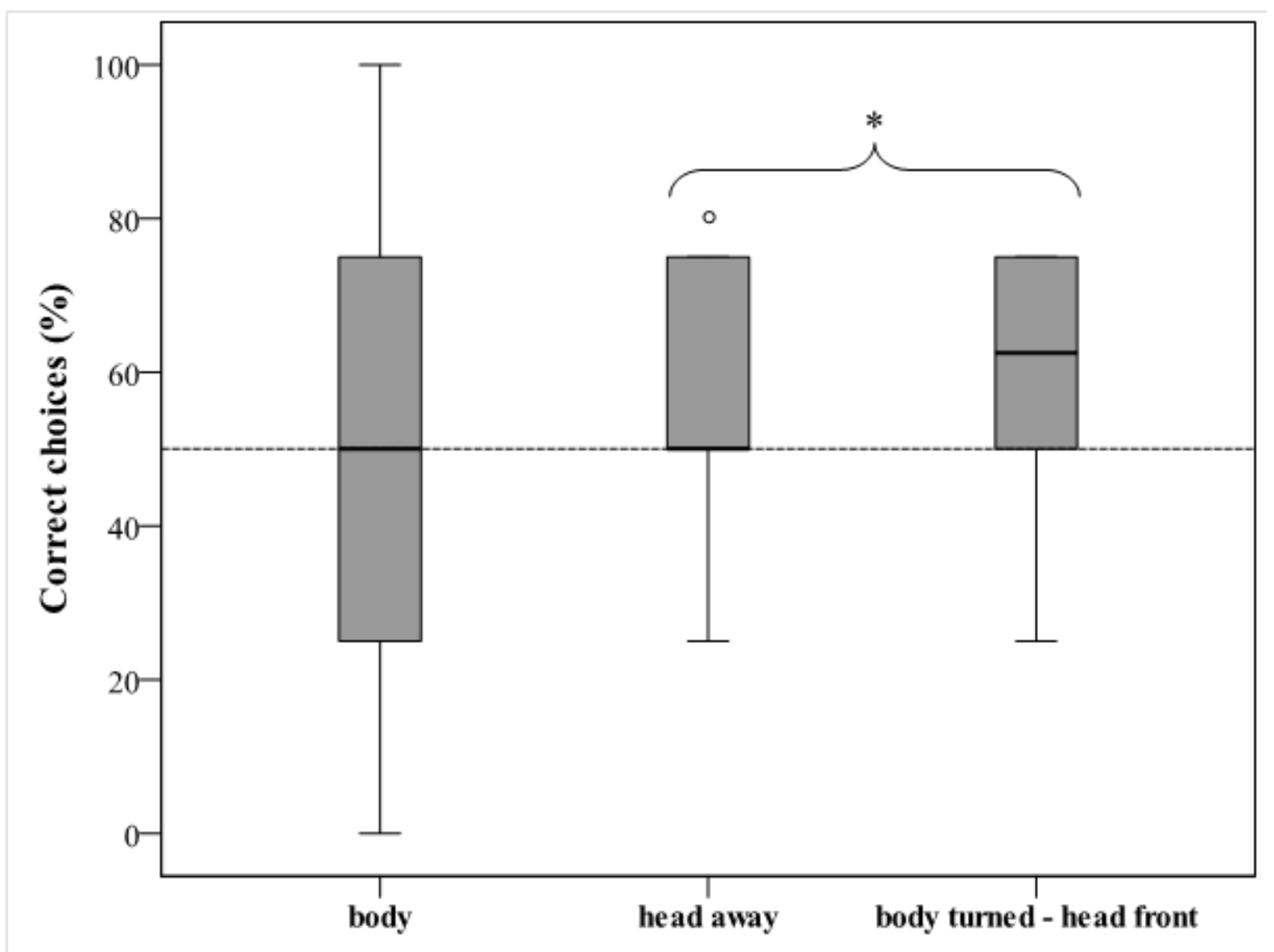

Fig. 3 Choice performances in the three different test conditions. Correct choices indicate the percentage of trials in which subjects chose the attentive experimenter. Box plots represent medians and upper and lower quartiles. Whiskers indicate $10 \%$ - and $90 \%$ range; $* P<.05$; ${ }^{\circ} P=.06$ (Wilcoxon signed rank, two tailed)

\subsection{Choice behaviour}

Performance was first analyzed separately for each condition. Pigs as a group showed a tendency to approach the attentive human in the head away condition (one-sample Wilcoxon signed ranks test, $T=24.0 ; N=16 ; P=.06$; two-tailed; see Table 1 and Fig. 3 ). In the body and body turned - head front condition, subjects performed on chance level $(T=28.0 ; N=16$; $P=.64$ respectively $T=48.0 ; N=16 ; P=.13$; two-tailed; see Table 1 ). Pooling those 
conditions where the only salient cue was the head direction (head away and body turnedhead front), we found a significant preference in subjects' choices for the person who was looking at them ( $T=48.0, N=16 ; P=.03$; two-tailed; see Fig. 3 ). No effects of sex (MannWhitney-U-test: $z=20.5 ; P=.313)$, age $(z=20.5 ; P=.252)$ or condition (Friedman-Test $=$ 2.711, $d f=2, P=.258$ ) emerged. Choice was neither affected by experimenter (binomial; $n=$ 192, $K=101, P=.516)$ nor by side $(n=192, K=97 ; P=.942)$.

\subsection{Response times}

Response times varied systematically as a function of performance $\left(F_{1,178}=4.9531 ; P=.027\right)$ but not of condition $\left(F_{2,171}=2.177 ; P=.117\right)$ and no interaction effect was found $\left(F_{2,177}=0.277 ; P=.758\right)$. Pigs took more time to choose the attentive person compared to the inattentive person, suggesting different response strategies (see Fig. 4). 


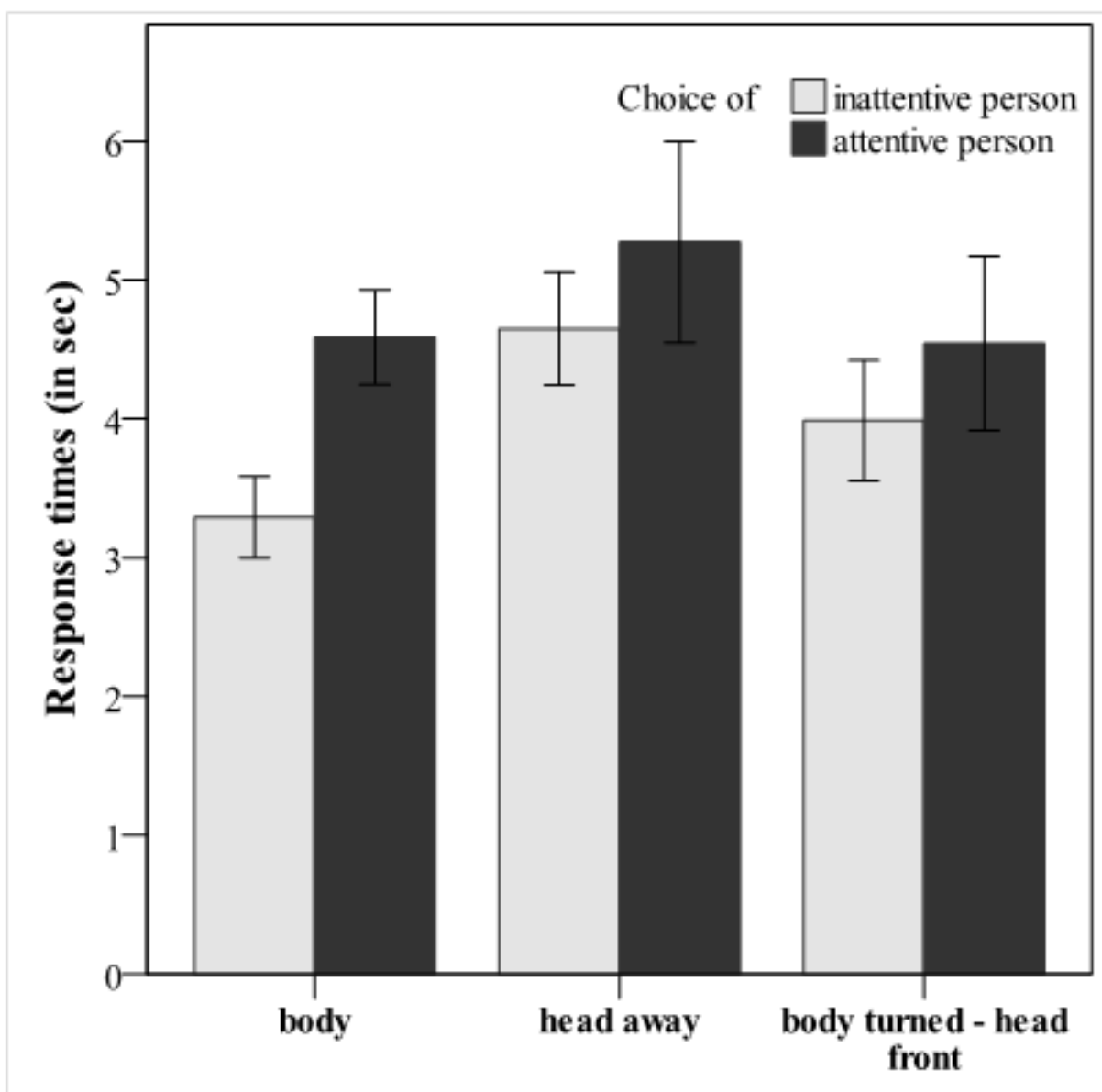

Fig. 4 Response times (i.e., time between entering the area and choice), separately for each condition and for choices of the attentive or inattentive experimenter. Error bars represent SEM.

\subsection{Additional behavioral parameters}

We assumed that longer response times for correct choices would have emerged due to the fact that pigs sometimes chose non-impulsively (i.e., changing their approach direction or inspecting both experimenters) rather than impulsively by going straight to one experimenter. The mean percentage of trials with a non-impulsive approach varied between $8 \%$ and $83 \%$ (corresponds to $1-10$ out of 12 trials; $\mathrm{M}=33 \%, \mathrm{SEM}=3.5$ ). As expected, response times were significantly longer when pigs chose non-impulsively compared to a straight approach to 
one of the experimenters $\left(F_{1,190}=17.633 ; P<.001\right)$. A trial-by-trial comparison revealed that in trials, in which subjects' chose non-impulsively, performance was significantly better than chance (Chi-square-Test: $\chi^{2}=4.0 ; P=.046$ ) while with an impulsive approach performance was on chance level $\left(\chi^{2}=0.0 ; P=1.0\right)$ (see Fig. 5).

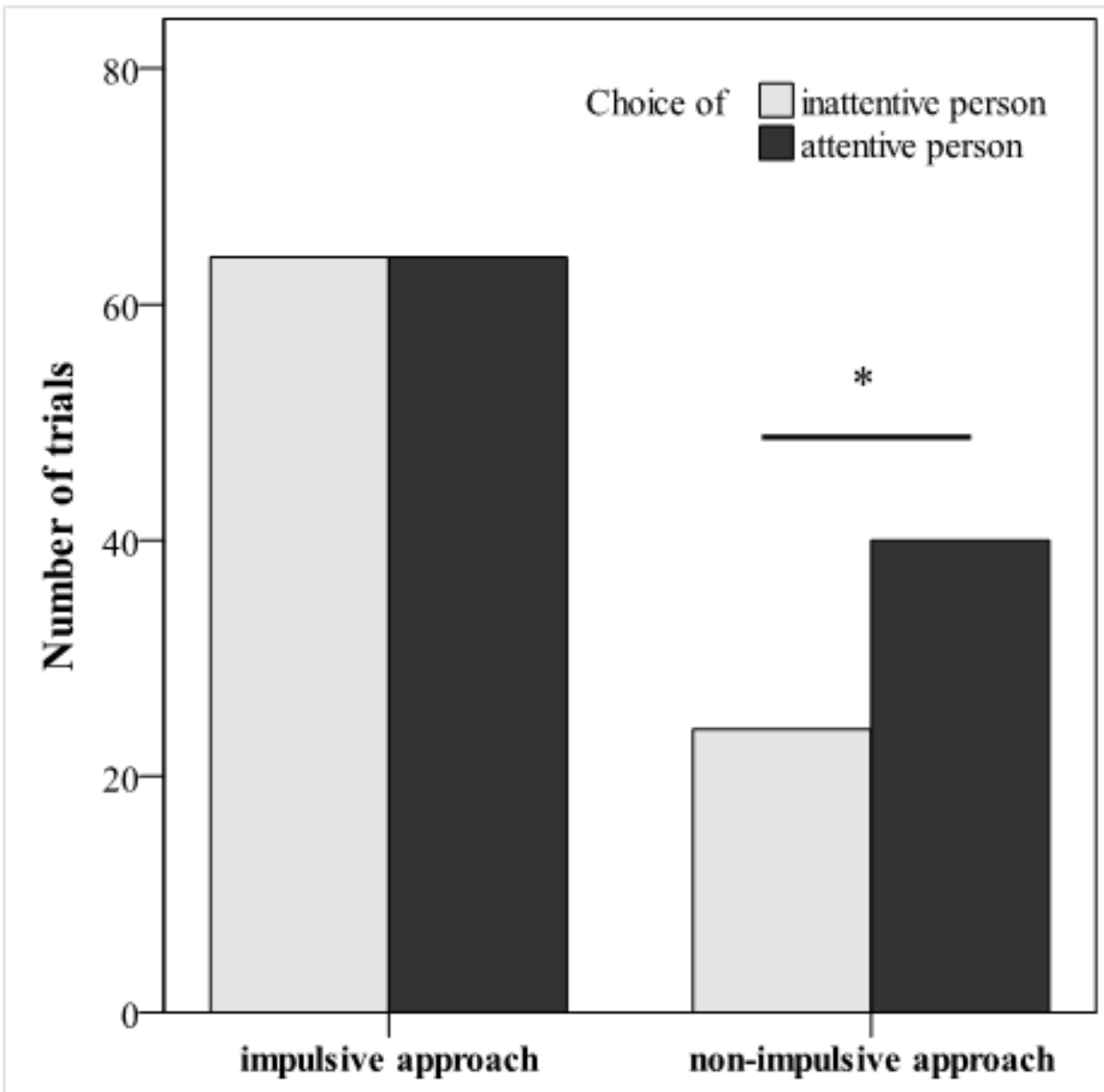

Fig. 5 Number of correct choices with (non-impulsive approach) or without gathering additional information (impulsive approach) $\left(\mathrm{Chi}^{2}\right.$-Test, $\left.* P<.05\right)$ 


\section{Discussion}

We investigated the ability of domestic pigs to differentiate between different attentive states of unfamiliar humans. When conditions were analyzed separately, there was a tendency to approach the attentive human in the head away condition. However, when individual pig's choice behavior was pooled across those two conditions where the position of the head was the only salient cue (i.e., head away and head front) we found a significant preference for the attentive person. In addition, contrary to a study with horses, where subjects had shorter response times when choosing the attentive experimenter (Proops and McComb, 2010), we found significantly longer response times in correct trials. We assume that longer response times are not due to any kind of uncertainty during decision making, as Proops and McComb (2010) argued for horses, but that, in contrast, shorter response times are the result of a too impulsive and therefore indifferent choice behavior of the subjects. Only in about one third of all trials subjects looked at both experimenters or changed direction, resulting in a significant increase of their response times and significantly more frequent choices of the attentive person. Further investigation on choice behavior in pigs should consider those differences in their approach styles. Due to the relatively high intra-individual variability in showing a nonimpulsive approach, it might be useful to examine in future studies whether this variability is linked to different personality traits or coping styles in pigs (e.g., Forkman et al., 1995).

Three arguments might serve to explain the relatively poor performance of pigs compared to the performance of dogs and horses (Gacsi et al., 2004; Proops and McComb, 2010), who performed correctly in about $70 \%$ of trials in a similar head away condition. First, pig's performance could be assigned to their poor experience with humans. Contrary to other studies (Call et al., 2003; Gacsi et al., 2004; Proops and McComb, 2010), our animals had no training history and their only experiences with humans before testing occured during feeding and cleaning with limited direct contact. However, as argued by Roberts and McPherson 
(2011), subjects should show a better performance in a test context that is more similar to previous food reinforced experiences with humans. Thus, one would expect a relatively high performance in the body condition as handlers normally orient their body towards the pigs when feeding them, which was not the case in the present study.

Second, different selective pressures through domestication may likely play a role to explain their performance. While some species are selected for working purposes or companionship (i.e., dogs and horses) that probably enhanced their skills in reading human communicative cues, pigs are mainly selected for growth and meat quality. To distinguish between the influence of human contact during ontogeny and selective pressures during domestication, a more comparative approach is needed (see Albiach-Serrano et al., 2012). For instance, the performance of adult animals with and without close human contact might be compared. Moreover, a comparison between adult domestic pigs and similarly reared wild boars can shed additional light on the effect of domestication. To broaden the picture of the effects of domestication in general, other domestic species like cats or goats, which already performed well in reading human social cues (Kaminski et al., 2005; Miklosi et al., 2005), should be tested with a similar paradigm.

Third, despite the fact that pig's are able to discriminate conspecifics and humans due to visual cues only (Koba and Tanida, 2001; McLeman et al., 2008), research on visual communication in pigs is rare. Thus we can only assume that the responsiveness to facial patterns and expressions is less important to pigs, probably due to their poor visual acuity (Zonderland et al., 2008), as compared to horses, dogs or primates with their elaborated mimic repertoire. This may also have affected pigs' choice behavior, relying less on faces and more on olfactory cues as sources of communicative value compared to most of the above mentioned species. 
Referring to the indifferent choice in the body condition, two factors may have affected pigs' performance. First, an avoidance of the human front, additionally indicated by generally longer response times in the head back compared to the body turned - head front condition may have developed during prior experiences with humans during handling (e.g., cleaning). Second, and more likely, pigs might have simply preferred human backs for other reasons, such as a preference for shoes. As noticed during handling, pigs were always highly motivated to chew on the shoes and bootlaces of the handler. Only in the body condition, just one of the two kneeling experimenters presented her back (and therefore her shoes as well) during testing, while in the other conditions, the body orientation of both experimenters was the same.

Compared to other studies, we had a relatively high drop-out rate, with about $45 \%$ of subjects to be excluded from the analysis. Especially subjects of Group 1 showed signs of aversion during training and test trials, even after repeated and prolonged exposure to the unfamiliar experimenters. They participated in a nutritional experiment for about five weeks before testing and had more restricted contact to humans than animals from Group 2. Although showing no signs of arousal in the sole presence of their handler, they stopped entering the test area during training or test trials when the unfamiliar experimenters were present. Since pigs can distinguish between familiar and unfamiliar persons (Tanida and Nagano, 1998; Koba and Tanida, 2001) they possibly might have perceived the experimenters as a threat. Side biases, on the other hand, were a less frequently observed problem but are commonly reported for choice paradigms in farm animals (Kaminski et al., 2005; Kendrick et al., 1995).

To date there is no study investigating cooperative behavior in pigs. Thus, the poor performance may be also attributed to a general low motivation in pig's to cooperate, either with con- or heterospecifics. Like previously shown for great apes (Hare et al., 2004), testing 
pigs in a similar, but competitive task could provide additional and potentially stronger evidence for pigs' use of humans' head and body orientation.

In summary, this study suggests that pigs might be able to use head cues to discriminate between different attentive states of humans by choosing the attentive rather than the inattentive experimenter. In addition, pigs had longer response times to approach the attentive experimenter which might be explained by a higher level of visual investigation of the test context and therefore, a more frequent choice of the person who paid attention to the subject. These results provide deeper insight into the socio-cognitive abilities of domestic pigs and can be used for a better understanding of human-animal interactions. Moreover, they can also serve as a basis to improve housing and handling methods to reduce welfare related problems. 


\section{Acknowledgments}

We would like to thank Volker Kutzner for building the pig pens, Mandy Koepcke and Petra Staps for test assistance, Leoni Spielmann for the drawings and Heidrun Nitzer, Manuela Zühl and Stephan Ebschke for reliability coding. 


\section{References}

Albiach-Serrano, A., Bräuer, J., Cacchione, T., Zickert, N. and Amici, F., 2012. The effect of domestication and ontogeny in swine cognition (Sus scrofa scrofa and S. S. domestica). Applied Animal Behaviour Science 141, 25-35.

Bania, A.E. and Stromberg, E.E., 2012. The effect of body orientation on judgments of human visual attention in Western Lowland Gorillas (Gorilla gorilla gorilla). Journal of Comparative Psychology. Online first.

Botting, J.L., Wiper, M.L. and Anderson, J.R., 2011. Brown (Eulemur fulvus) and ring-tailed lemurs (Lemur catta) use human head orientation as a cue to gaze direction in a food choice task. Folia Primatologica 82, 165-176.

Broom, D.M., Sena, H. and Moynihan, K.L., 2009. Pigs learn what a mirror image represents and use it to obtain information. Animal Behaviour 78, 1037-1041.

Bulloch, M.J., Boysen, S.T. and Furlong, E.E., 2008. Visual attention and its relation to knowledge states in chimpanzees, Pan troglodytes. Animal Behaviour 76, 1147-1155.

Call, J., Bräuer, J., Kaminski, J. and Tomasello, M., 2003. Domestic dogs (Canis familiaris) are sensitive to the attentional state of humans. Journal of Comparative Psychology 117, 257-263.

Call, J. and Tomasello, M., 2008. Does the chimpanzee have a theory of mind? 30 years later. Trends in Cognitive Sciences 12, 187-192.

Flombaum, J.I. and Santos, L.R., 2005. Rhesus monkeys attribute perceptions to others. Current Biology 15, 447-452.

Forkman, B., Furuhaug, I.L. and Jensen, P., 1995. Personality, coping patterns, and aggression in piglets. Applied Animal Behaviour Science 45, 31-42. 
Gácsi, M., Miklosi, A., Varga, O., Topal, J. and Csanyi, V., 2004. Are readers of our face readers of our minds? Dogs (Canis familiaris) show situation-dependent recognition of human’s attention. Animal Cognition 7, 144-153.

Hare, B., Brown, M., Williamson, C. and Tomasello, M.. 2002. The domestication of social cognition in dogs. Science 298, 1634-1636.

Hare, B. and Tomasello, M., 2004. Chimpanzees are more skilful in competitive than in cooperative cognitive tasks. Animal Behaviour 68, 571-581.

Hare, B. and Tomasello, M. 2005., The emotional reactivity hypothesis and cognitive evolution. Trends in Cognitive Sciences 9, 464-465.

Hattori, Y., Kuroshima, H. and Fujita, K., 2007. I know you are not looking at me: capuchin monkeys' (Cebus apella) sensitivity to human attentional states. Animal Cognition 10, 141-148.

Held, S., Mendl, M., Devereux, C. and Byrne, R.W., 2000. Social tactics of pigs in a competitive foraging task: the 'informed forager' paradigm. Animal Behaviour 59, 569-576.

Held, S., Mendl, M., Devereux, C. and Byrne, R.W., 2001. Behaviour of domestic pigs in a visual perspective taking task. Behaviour 138, 1337-1354.

Held, S., Mendl, M., Devereux, C. and Byrne, R.W., 2002. Foraging pigs alter their behaviour in response to exploitation. Animal Behaviour 64, 157-166.

Held, S., Baumgartner, J., KilBride, A., Byrne, R.W. and Mendl, M., 2005. Foraging behaviour in domestic pigs (Sus scrofa): remembering and prioritizing food sites of different value. Animal Cognition 8, 114-121.

Hostetter, A.B., Cantero, M. and Hopkins, W.D., 2001. Differential use of vocal and gestural communication by chimpanzees (Pan troglodytes) in response to the attentional status of a human (Homo sapiens). Journal of Comparative Psychology 115, 337-343. 
Kaminski, J., Call, J. and Tomasello, M., 2004. Body orientation and face orientation: two factors controlling apes' begging behavior from humans. Animal Cognition 7, 216223.

Kaminski, J., Riedel, J., Call, J. and Tomasello, M., 2005. Domestic goats, Capra hircus, follow gaze direction and use social cues in an object choice task. Animal Behaviour 69, 11-18.

Kendrick, K.M., Atkins, K., Hinton, M.R., Broad, K.D., Fabre-Nys, C. and Keverne, B., 1995. Facial and vocal discrimination in sheep. Animal Behaviour 49, 1665-1676.

Koba, Y. and Tanida, H., 2001. How do miniature pigs discriminate between people?: Discrimination between people wearing coveralls of the same colour. Applied Animal Behaviour Science 73, 45-58.

Kornum, B.R. and Knudsen, G.M., 2011. Cognitive testing of pigs (Sus scrofa) in translational biobehavioral research. Neuroscience \& Biobehavioral Reviews 35, 437451.

Kouwenberg, A.-L., Walsh, C.J., Morgan, B.E. and Martin, G.M., 2009. Episodic-like memory in crossbred Yucatan minipigs (Sus scrofa). Applied Animal Behaviour Science 117, 165-172.

Kummer, H., 1967. Tripartite relations in hamadryas baboons. In: S.A. Altmann (Editor), Social communication among primates, University of Chicago Press, Chicago, pp. 6372.

Mendl, M., Laughlin, K. and Hitchcock, D., 1997. Pigs in space: spatial memory and its susceptibility to interference. Animal Behaviour 54, 1491-1508.

Mendl, M. and Paul, E.S., 2008. Do animals live in the present?: Current evidence and implications for welfare. Applied Animal Behaviour Science 113, 357-382. 
McLeman, M.A., Mendl, M.T., Jones, R.B. and Wathes, C.M., 2008. Social discrimination of familiar conspecifics by juvenile pigs, Sus scrofa: Development of a non-invasive method to study the transmission of unimodal and bimodal cues between live stimuli. Applied Animal Behaviour Science 115, 123-137.

Miklósi, Á., Pongracz, P., Lakatos, G., Topal, J. and Csanyi, V., 2005. A comparative study of the use of visual communicative signals in interactions between dogs (Canis familiaris) and humans and cats (Felis catus) and humans. Journal of Comparative Psychology 119, 179-186.

Povinelli, D.J. and Eddy, T.J., 1996. What young chimpanzees know about seeing. Monographs of the Society for Research in Child Development 61, 1-191.

Proops, L. and McComb, K., 2010. Attributing attention: the use of human-given cues by domestic horses (Equus caballus). Animal Cognition 13, 197-205.

Roberts, W. and MacPherson, K., 2011. Theory of mind in dogs: is the perspective-taking task a good test? Learning \& Behavior 39, 303-305.

Sandel, A.A., MacLean, E.L. and Hare, B., 2011. Evidence from four lemur species that ringtailed lemur social cognition converges with that of haplorhine primates. Animal Behaviour 81, 925-931.

Tanida, H. and Nagano, Y., 1998. The ability of miniature pigs to discriminate between a stranger and their familiar handler. Applied Animal Behaviour Science 56, 149-159.

Tempelmann, S., Kaminski, J. and Liebal, K., 2011. Focus on the essential: all great apes know when others are being attentive. Animal Cognition 14, 433-439.

Udell, M.A.R., Dorey, N.R. and Wynne, C.D.L., 2008. Wolves outperform dogs in following human social cues. Animal Behaviour, 76, 1767-1773.

Udell, M., Dorey, N. and Wynne, C., 2011. Can your dog read your mind? Understanding the causes of canine perspective taking. Learning \& Behavior 39, 289-302. 
Umberto, A., 2007. Pigs and humans. Oxford University Press, Oxford, 454 pp.

Virányi, Z. and Range, F., 2011. Evaluating the logic of perspective-taking experiments. Learning \& Behavior 39, 306-309.

Zonderland, J.J., Cornelissen, L., Wolthuis-Fillerup, M. and Spoolder, H.A.M., 2008. Visual acuity of pigs at different light intensities. Applied Animal Behaviour Science 111, 28-37. 